\title{
SISTEM PENGATURAN LAMPU LALU LINTAS BERDASARKAN ESTIMASI PANJANG ANTRIAN MENGGUNAKAN PENGOLAHAN CITRA
}

\author{
Adzikirani $^{1}$, Rosa Andrie Asmara ${ }^{2}$, Deddy Kusbianto P. A $^{3}$ \\ 1,2,3 Teknik Informatika, Teknologi Informasi, Polteknik Negeri Malang \\ 1adzikirani1@gmail.com, ${ }^{2}$ rosaandrie@gmail.com, ${ }^{3}$ deddy_kusbianto@ polinema.ac.id
}

\begin{abstract}
Abstrak
Saat ini salah satu penyebab kemacetan adalah lampu lalu lintas yang menggunakan waktu yang tetap sedangkan volume kendaraan selalu berubah-, sehingga lampu lalu lintas menjadi kurang efektif. Maka dibutuhkan metode untuk menghitung lama lampu lalu lintas menyala dengan waktu sesuai dengan jumlah kendaraan.

Sistem ini mengimplementasikan 4 kamera pada persimpangan. Kamera mengambil gambar saat jalur sedang kosong sebagai acuan, dan mengambil gambar setiap sequence sebagai input. Gambar diproses menggunakan pengolahan citra, dari merubah format RGB menjadi grayscale, dilakukan proses subtraction dengan gambar acuan, penambahan brightness, merubah format grayscale menjadi biner dengan Otsu's threshold dan menghitung jumlah objek sebagai input dari logika fuzzy tsukamoto yang menghasilkan lama lampu hijau menyala. Sedangkan lama lampu merah menyala dihitung dengan menjumlahkan lama lampu hijau menyala dari jalur lainnnya Penggunaan 4 buah input dimaksudkan agar sistem memperhatikan jumlah antrian dari setiap jalur dan memperhatikan sebaran kepadatan, Sehingga hasil lama lampu merah dan lampu hijau menyala dapat berubah-ubah sesuai dengan sebaran kepadatan antrian.

Semakin terang kondisi jalan, semakin tinggi tingkat akurasi yang didapatkan. Pada pagi hari, didapatkan nilai error $1.74 \%$, pada siang hari sebesar $9 \%$, pada malam hari dengan penerangan normal sebesar $21 \%$ dan pada malam hari dengan tambahan penerangan sebesar $15 \%$.
\end{abstract}

Kata kunci : Logika Fuzzy, Pengolahan Citra

\section{Pendahuluan}

Saat ini keberadaan alat-alat transportasi seperti mobil, truk, dan sepeda motor. Sudah begitu banyak, hampir disetiap tempat alat transportasi selalu tersedia. Bahkan untuk lebih cepat dan hemat biaya sekarang ini hampir semua orang sudah memiliki satu alat transportasi pribadi yang selalu di gunakan sehari-hari. Namun ironisnya semakin banyak kendaraan di jalan raya efek macet pun semakin menjadi jadi. Terutama pada persimpangan jalan sering kali terjadi kemacetan yang disebabkan pengaturan lampu lalu lintas yang tidak baik. Selain itu jumlah kepadatan yang berubah rubah setiap saat membuat lama lampu lalu lintas menyala menjadi tidak efektif

Penentuan lamanya lampu lalu lintas di suatu tempat pada umumnya berdasarkan survei yang dilaksanakan.Dan merupakan lama lampu yang tetap dan tidak berubah-ubah.Sehingga dari permasalahan permasalahan tersebut pada tugas akhir ini penulis akan membuat sistem dengan judul "Sistem Pengaturan Lampu Lalu Lintas Berdasarkan Estimasi Panjang Antrian Menggunakan Pengolahan Citra" untuk mengatur lama lampu lalu lintas menyala berdasarkan panjang antrian pada persimpangan yang diukur menggunakan kamera dan diolah menggunakan Pengolahan Citra Digital serta dihitung menggunakan logika Fuzzy.

Sistem akan menangkap gambar pada persimpangan yang nantinya diolah menggunakan pengolahan citra, sehingga didapatkan estimasi panjang antrian yang nantinya akan dibandingkan dengan jalur lain dan digunakan menjadi patokan untuk mengatur lamanya setiap lampu lalu lintas menyala yang dihitung menggunakan Logika Fuzzy agar dapat menghasilkan keputusan yang lebih adil dan lebih manusiawi.Sehingga dapat mengurangi kemacetan.

\section{Landasan Teori}

\subsection{Citra Digital}

Citra digital adalah gambar dua dimensi yang ditampilkan pada layar komputer sebagai himpunan atau diskrit nilai digital. Citra Digital dibentuk oleh kumpulan titik yang dinamakan piksel (pixel atau picture element). 


\subsection{Logika Fuzzy}

Logika fuzzy adalah suatu proses pengambilan keputusan berbasis aturan yang bertujuan untuk memecahkan masalah, dimana sistem tersebut sulit untuk dimodelkan atau terdapat ambiguitas dan ketidakjelasan yang berlimpah. Logika fuzzy ditentukan oleh persamaan logika bukan dari persamaan diferensial komplek dan berasal dari pemikiran yang mengidentifikasi serta mengambil keuntungan dari grayness antara dua ekstrem. Sistem logika fuzzy terdiri dari himpunan fuzzy dan aturan fuzzy. Subset fuzzy merupakan himpunan bagian yang berbeda dari variabel input dan output. Aturan fuzzy berhubungan dengan variabel masukan dan variabel output melalui subset.

\section{Metodologi Penelitian}

Mekanisme berjalannya "Sistem Pengaturan Lampu Lalu Lintas Berdasarkan Estimasi Panjang Antrian Menggunakan Pengolahan Citra" yaitu:

1. Kamera akan mengambil citra setiap jalur pada saat persimpangan kosong untuk dijadikan acuan latar belakang pada saat melakukan proses image differencing.

2. Menentukan Region Of Interest (ROI) untuk memilih bagian dari citra sesuai keinginan user.

3. Kamera akan mengambil citra waktu yang ditentukan setiap jalur pada saat ada antrian sebagai inputan citra yang akan diproses.

4. Citra setiap jalur yang telah di ambil akan diubah menjadi abu-abu menggunakan proses grayscaling agar citra yang dihasilkan tidak berbeda dengan citra acuan yang telah di ambil sebelumnya.

5. Citra yang telah di grayscale akan di cari perbedaannya menggunakan metode image Subtraction yaitu mengurangkan citra input yang di ambil dengan citra acuan latar belakang yang telah di ambil sebelumnya. Sehingga menghasilkan citra baru yang berisi objek yang berada pada jalur tersebut.

6. Citra hasil Subtraction akan di tambah brightness nya agar citra menjadi semakin jelas dengan rumus brightness :

Brightness $=$ sqrt $\left(0.299 \mathrm{R}^{2}+0.587 \mathrm{G}^{2}+0.114 \mathrm{~B}^{2}\right)$

7. Citra baru yang berisi objek akan di ubah menjadi biner menggunakan metode Otsu's thresholding agar citra dapat di hitung seberapa panjang antrian atau objek yang terdapat pada citra tersebut.

8. Output dari proses pengolahan citra berupa berapa banyak objek yang ditemukan.

9. Masing masing panjang antrian yang telah dihasilkan akan di buat input untuk menentukan lama setiap lampu lalu lintas menyala di setiap jalurnya menggunakan logika fuzzy.
10. Pada proses penghitungan menggunakan logika fuzzy Ada 2 variabel fuzzy yang akan dimodelkan, yaitu:

1. Membership Function panjang antrian, terdiri-atas 3 himpunan fuzzy yaitu: banyak, sedang, dan sedikit, yang diadopsi dari penelitian Yoga Yudanto (2013) yang berjudul Optimalisasi Lampu Lalu Lintas dengan FuzzyLogic.

Dengan aturan :

- Banyak : Lebih dari 20000 pixel hitam yang mewakili 10 mobil atau sepanjang jalan prototype

- Sedang : 12500 sampai 20000 pixel hitam yang mewakili 5 mobil atau setengah dari panjang jalan prototype

- Sedikit : Kurang Dari 5000 pixel hitam yang mewakili 1 atau 2 mobil

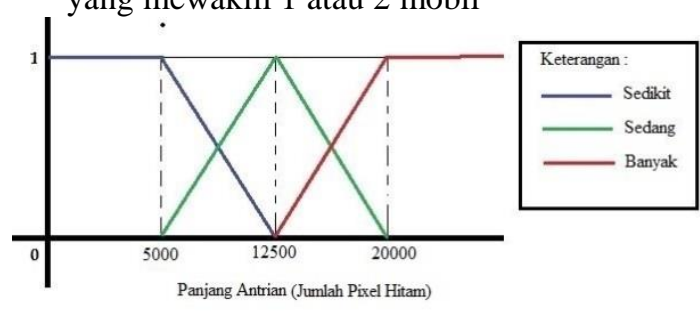

Gambar 1. Himpunan Fuzzy Panjang Antrian

$$
\begin{aligned}
& \begin{array}{l}
\mu \text { Sedikit }(x) \\
=\left\{\begin{aligned}
\frac{12500-x}{12500-5000}, & 5000 \leq x \leq 12500 \\
0, & x>12500
\end{aligned}\right\}
\end{array} \\
& =\left\{\begin{aligned}
\frac{x-5000}{12500-5000}, & 5000 \leq x \leq 12500 \\
\frac{20000-x}{20000-12500}, & 12500 \leq x \leq 20000 \\
0, & x>20000
\end{aligned}\right\} \\
& \begin{array}{l}
\mu \operatorname{Banyak}(x) \\
=\left\{\begin{array}{rl}
0,12500 & x<12500 \\
20000-12500, & 12500 \leq x \leq 20000 \\
1, & x>20000
\end{array}\right\}
\end{array}
\end{aligned}
$$

Fungsi Keanggotaan Himpunan Fuzzy Panjang Antrian

2. Variabel lama lampu hijau, terdiri-atas 4 himpunan fuzzy yaitu: sangat lama, lama, sedang, dan cepat.

Dengan aturan :

$$
\begin{aligned}
& \text { - } \quad \text { Sangat lama = } 80 \text { detik } \\
& \text { - } \quad \text { Sama }=55 \text { detik } \\
& \text { - } \quad \text { Cedang = } 35 \text { detik } \\
& \text { - }
\end{aligned}
$$

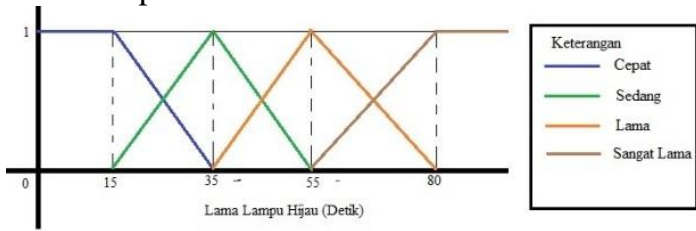

Gambar 2. Himpunan Fuzzy Lama Lampu Hijau 


$$
\begin{aligned}
& \mu \text { Cepat }(x)=\left\{\begin{array}{cl}
1, & x<15 \\
\frac{35-x}{35-15,} & 15 \leq x \leq 35 \\
0, & x>35
\end{array}\right\} \\
& \mu \text { Sedang }(x)=\left\{\begin{array}{cl}
\frac{x-15}{35-15}, & 15 \leq x \leq 35 \\
\frac{55-x}{55-35}, & 35 \leq x \leq 55 \\
0, & x>55
\end{array}\right\} \\
& \mu \text { Lama }(x)=\left\{\begin{array}{cl}
\frac{x-35}{55-35}, & 35 \leq x \leq 55 \\
\frac{80-x}{80-55,} & 55 \leq x \leq 80 \\
0, & x>80
\end{array}\right\}, \quad x<55 \\
& \mu \text { Banyak }(x)=\left\{\begin{array}{cl}
\frac{x-55}{80-55}, & 55 \leq x \leq 80 \\
1, & x>80
\end{array}\right\}
\end{aligned}
$$

Fungsi Keanggotaan Himpunan Fuzzy Lama Lampu Hijau

Sehingga dari proses di atas menghasilkan output berupa lama lampu hijau menyala dari tiaptiap jalur .Sedangkan lama lampu merah akan di hitung dengan cara menjumlahkan lama lampu hijau menyala dari jalur lainnya.

\section{Analisis dan Perancangan}

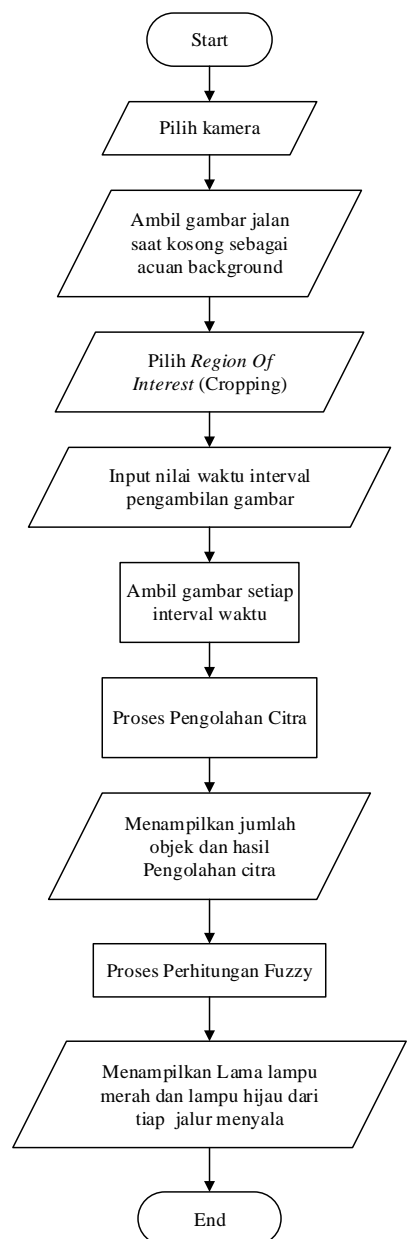

Gambar 3. Alur Sistem

\section{Implementasi}

\subsection{Implementasi Prototype}

Prototype persimpangan dibuat dalam bentuk 4 persimpangan jalan dengan ukuran 1 meter persegi.4 buah kamera webcam usb di letakan di masing-masing jalur untuk mengambil gambar dari jalur di depannya.

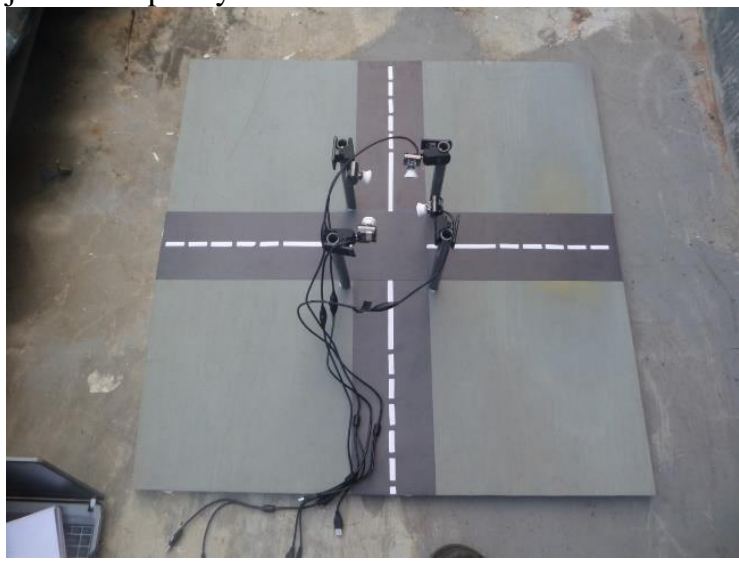

Gambar 4. Prototype Persimpangan Jalan

\subsection{Implementasi Pengambilan Background}

Kamera akan mengambil citra setiap jalur pada saat persimpangan kosong untuk dijadikan acuan latar belakang pada saat melakukan proses image differencing.

\subsection{Implementasi Cropping}

Menentukan Region Of Interest (ROI) untuk memilih bagian dari citra sesuai keinginan user.Cropping digunakan agar bagian yang tidak diinginkan dari jalur tersebut tidak masuk dalam proses perhitungan.Region dari setiap jalur memiliki luas yang sama, mengacu pada pengaturan di jalur pertama.

\subsection{Implementasi Grayscale}

Citra setiap jalur yang telah di ambil akan diubah menjadi abu-abu menggunakan proses grayscale menggunakan grayscale luminance agar citra yang dihasilkan tidak berbeda dengan citra acuan yang telah di ambil sebelumnya.Citra yang telah di ambil akan dilakukan proses ekstraksi RGB, sehingga dihasilkan nilai RGB dari setiap pixel dari citra.lalu kemudian diubah nilainya menggunakan rumus luminosity diatas.

\subsection{Implementasi Substraksi}

Citra akan di cari perbedaannya menggunakan metode image Subtraction yaitu mengurangkan citra input yang di ambil dengan citra acuan latar belakang yang telah di ambil sebelumnya. Sehingga menghasilkan citra baru yang berisi objek yang berada pada jalur tersebut. 


\subsection{Implementasi Brightness}

Citra hasil Subtraction akan di tambah brightness nya agar citra menjadi semakin jelas .Penambahan brightness dimaksdkan agar citra objek yang telah ditemukan menjadi semakin jelas ,menggunakan HSP Color Model Sehingga menambahkan nilai brightness dari masing-masing pixel yang nantinya ditambahkan pada pixel citra sehingga menghasilkan citra yang lebih terang.

\subsection{Implementasi Otsu's Threshold}

Citra baru yang berisi objek akan di ubah menjadi biner menggunakan metode Otsu's thresholding agar citra dapat di hitung seberapa panjang antrian atau objek yang terdapat pada citra tersebut.

\subsection{Implementasi Perhitungan Jumlah Objek}

Citra yang telah berupa citra biner dihitung jumlah citra dengan nilai RGB 0 atau hitam, yang merupakan objek yang telah ditemukan.Sehingga menemukan jumlah Objek masing masing jalur persimpangan.

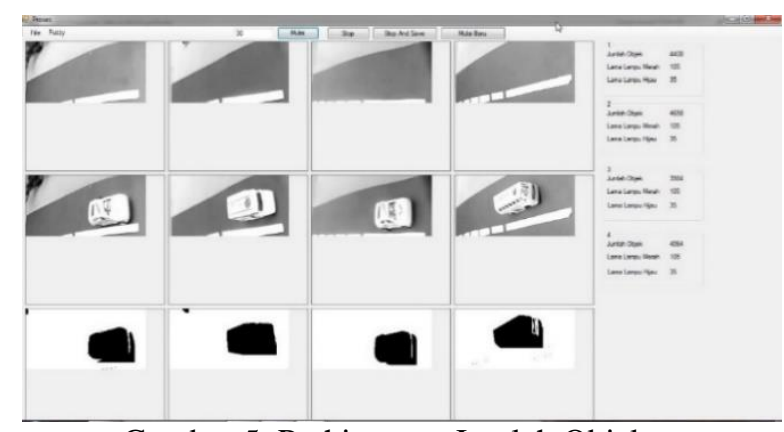

Gambar 5. Perhitungan Jumlah Objek

\subsection{Implementasi Fuzzy}

Proses implementasi logika fuzzy untuk menghitung lama lampu hijau menyala dengan 4 buah input, yang berasal dari jumlah objek masingmasing jalur yang telah di proses sebelumnya.

\section{Pengujian}

Pengujian dilakukan untuk menjamin dan memastikan bahwa sistem yang dirancang dapat berjalan seperti yang diharapkan. Strategi pengujian yang digunakan yaitu:

\subsection{Pengujian Prototype}

Pengujian prototype dilakukan untuk melihat apakah prototype yang dibuat dapat digunakan untuk aplikasi,kamera yang dapat menangkap gambar dari masing masing jalur dan jalur yang dapat menampung mobil .

\subsection{Pengujian dan Pembahasan Proses \\ Pengolahan Citra}

Pengujian proses pengolahan citra dilakukan untuk mengetahui apakah proses pengolahan citra berjalan secara baik dan dapat menemukan objek dari citra yang telah diambil.

Tabel 1. Pengujian Proses Pengolahan Citra

\begin{tabular}{|c|c|c|c|c|}
\hline No. & $\begin{array}{l}\text { Citra } \\
\text { Acuan } \\
\text { (Back- } \\
\text { ground) }\end{array}$ & $\begin{array}{l}\text { Citra } \\
\text { Objek }\end{array}$ & Hasil & $\begin{array}{l}\text { Jum- } \\
\text { lah } \\
\text { Pixel } \\
\text { dari } \\
\text { Objek }\end{array}$ \\
\hline 1 & & & & 3400 \\
\hline 2 & & & & 17984 \\
\hline 3 & & & & 6900 \\
\hline 4 & & & & 15288 \\
\hline 5 & & & & 18760 \\
\hline 6 & & & & 13773 \\
\hline
\end{tabular}

Pada pengujian pengolahan citra dilakukan terhadap 6 buah citra objek dengan 6 buah citra acuan dan menghasilkan citra hasil yang merupakan hasil proses pengolahan citra.Masing-masing menghasilkan hitungan jumlah citra yang berbeda.Jumlah citra mobil kurang lebih 3000 untuk satu mobil. Sehingga dapat disimpulkan bahwa hasil dari proses pengolahan citra sudah sesuai dengan yang diharapkan.Pengujian juga dilakukan dengan mengambil objek dengan jumlah mobil mulai dari 1 hingga 10 sehingga menghasilkan jumlah objek yang berbeda-beda, hasil dari pengujian dapat dilihat pada Gambar 6 . 


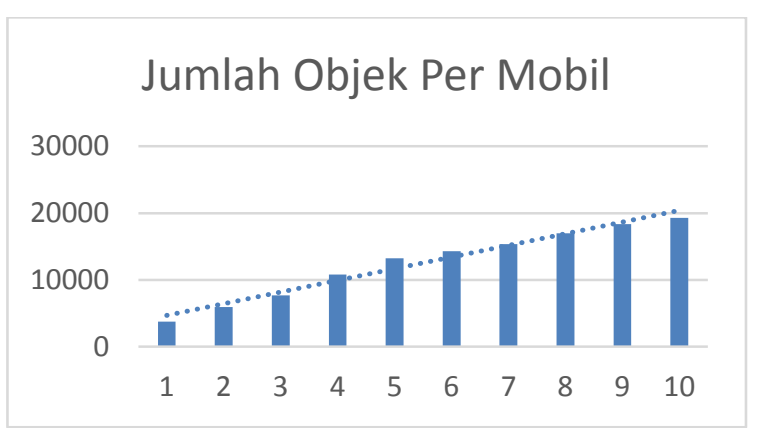

Gambar 6. Grafik Jumlah Objek

\subsection{Pengujian Pengaruh Pencahayaan pada Akurasi Jumlah Objek}

Pengujian pengaruh pencahayaan pada akurasi jumlah objek mobil dilakukan dengan cara mengambil gambar dengan kondisi penerangan berbeda sehingga dapat diketahui akurasi penghitungan jumlah objek.

Tabel 2. Pengaruh Pencahayaan pada Akurasi Jumlah Objek

\begin{tabular}{|c|c|c|c|c|}
\hline No. & Kondisi & $\begin{array}{l}\text { Citra } \\
\text { Objek }\end{array}$ & $\begin{array}{l}\text { Hasil } \\
\text { Proses } \\
\text { Pengolah- } \\
\text { an Citra }\end{array}$ & $\begin{array}{l}\text { Jum- } \\
\text { lah } \\
\text { Pixel } \\
\text { dari } \\
\text { Objek }\end{array}$ \\
\hline 1. & $\begin{array}{l}\text { Pagi } \\
\text { hari } \\
\text { cerah }\end{array}$ & & & 5932 \\
\hline 2. & $\begin{array}{l}\text { Pagi } \\
\text { hari } \\
\text { cerah }\end{array}$ & & & 3224 \\
\hline 3. & $\begin{array}{l}\text { Siang } \\
\text { hari } \\
\text { cerah }\end{array}$ & & & 6900 \\
\hline 4. & $\begin{array}{l}\text { Siang } \\
\text { hari } \\
\text { ber- } \\
\text { awan }\end{array}$ & & & 5288 \\
\hline 5. & $\begin{array}{l}\text { Malam } \\
\text { hari } \\
\text { pene- } \\
\text { rangan } \\
\text { normal }\end{array}$ & $1 .=$ & & 2696 \\
\hline 6. & $\begin{array}{l}\text { Malam } \\
\text { hari } \\
\text { pene- } \\
\text { rangan } \\
\text { normal }\end{array}$ & I & 11 & 4431 \\
\hline 7. & $\begin{array}{l}\text { Malam } \\
\text { hari } \\
\text { pene- } \\
\text { rangan } \\
\text { ditam- } \\
\text { bah }\end{array}$ & & & 2638 \\
\hline
\end{tabular}

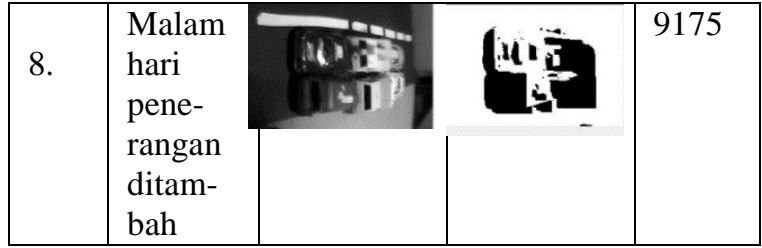

Dengan mengacu pada grafik jumlah pixel objek pada gambar 6, maka dapat dihitung akurasi dari pengaruh pencahayaan pada system.

Pagi hari :

Siang Hari

$$
\text { Error }=\frac{19156-18500}{37656} \times 100 \%=1.74 \%
$$

$$
\text { Error }=\frac{22160-18500}{40660} \times 100 \%=9 \%
$$

Malam Hari Penerangan Normal

$$
\text { Error }=\frac{7127-11000}{18127} \times 100 \%=21 \%
$$

Malam Hari dengan tambahan penerangan

$$
\text { Error }=\frac{11813-16200}{28013} \times 100 \%=15 \%
$$

\subsection{Pengujian dan Pembahasan Logika Fuzzy}

Proses logika fuzzy untuk menghitung lama lampu hijau menyala dengan 4 buah input.

$$
\begin{aligned}
& \text { Input jalur } 1=6900 \\
& \text { Input jalur } 2=12000 \\
& \text { Input Jalur 3 }=10200 \\
& \text { Input Jalur 4 }=18900
\end{aligned}
$$

- Proses Fuzzyfikasi untuk menekankan keanggotaan dari masing masing inputan pada Membership Function panjang antrian.

Input $1=6900$

$$
\begin{aligned}
& \mu \operatorname{Sedikit}(x)=\frac{12500-6900}{12500-5000}=0.7467 \\
& \mu \operatorname{Sedang}(x)=\frac{6900-5000}{12500-5000}=0.2533
\end{aligned}
$$

Input $2=12000$

$$
\begin{aligned}
& \mu \operatorname{Sedikit}(x)=\frac{12500-12000}{12500-5000}=0.0067 \\
& \mu \operatorname{Sedang}(x)=\frac{12000-5000}{12500-5000}=0.9333
\end{aligned}
$$

Input $3=10200$

$$
\begin{aligned}
& \mu \operatorname{Sedikit}(x)=\frac{12500-10200}{12500-5000}=0.3067 \\
& \mu \operatorname{Sedang}(x)=\frac{10200-5000}{12500-5000}=0.6933
\end{aligned}
$$

Input $4=18900$

$$
\begin{aligned}
& \mu \operatorname{Banyak}(x)=\frac{18900-12500}{20000-12500}=0.8533 \\
& \mu \operatorname{Sedang}(x)=\frac{20000-18900}{20000-12500}=0.1467
\end{aligned}
$$

- Lalu aplikasikan Fuzzy Input yang dihasilkan dari masing - masing Membership Function ke semua Inference / Rule yang sesuai dengan 
Inference / Rule yang tersedia. Diimplikasikan menggunakan fungsi minimum atau AND kepada rule yang cocok dengan himpunan fuzzy.

- Lalu hasil dari implikasi tersebut yang akan digunakan dalam proses penegasan atau Defuzzifikasi. dengan menggunakan Height Method atau mencari nilai maksimum dari implikasi tersebut, dengan output variabel linguistik. Atau menggunakan Weight Of Average dengan cara sebagai berikut :

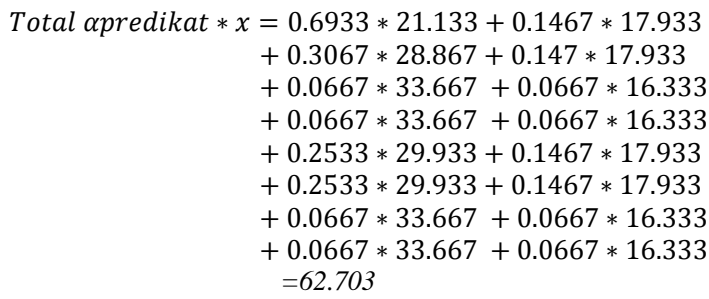

Sehingga ditemukan nilai lampu hijau menyala menurut perhitungan manual adalah 23.871 detik.Sedangkan dalam aplikasi perhitungan fuzzy dengan input diatas adalah seperti gambar berikut:

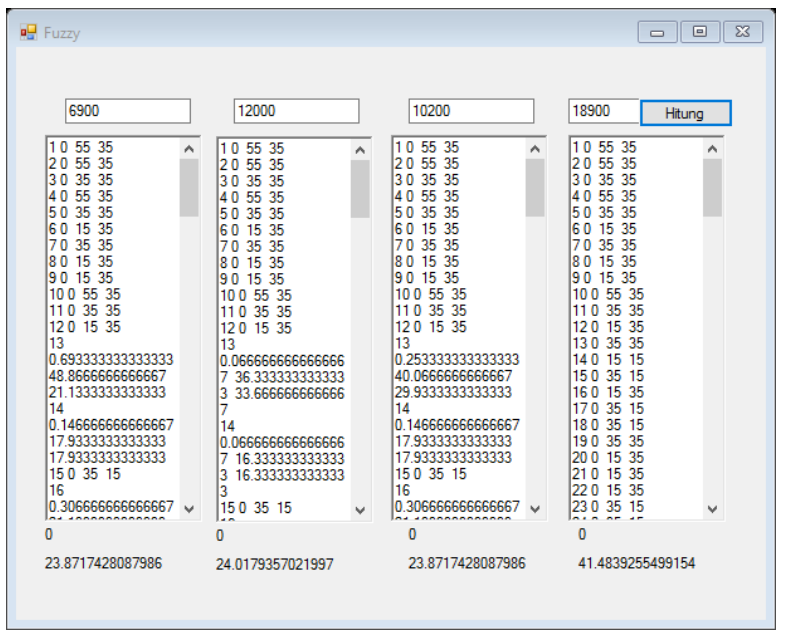

Gambar 7. Proses Fuzzy

Proses fuzzy pada aplikasi adalah dengan cara fuzzyfikasi jumlah objek terhadap himpunan anggota fuzzy, sehingga ditemukan keanggotaan dari masing masing input. Lalu proses implementasi nilai keanggotaan dari masing-masing input terhadap rule fuzzy yang telah ada, dan kemudian proses defuzzyfikasi sehingga menghasilkan nilai output yaitu lama lampu hijau menyala dari setiap jalur.

Proses fuzzy pada aplikasi pada jalur pertama dengan menggunakan input yang sama,yaitu pada label pada kolom pertama adalah 23.8717428087986 detik.Tidak berbeda dengan hasil perhitungan manual yaitu 23.871 detik.

\section{Kesimpulan dan Saran}

\subsection{Kesimpulan}

Berdasarkan penelitian yang dilaksanakan oleh penulis pada Sistem Pengaturan Lampu Lalu Lintas Berdasarkan Estimasi Panjang Antrian Menggunakan Pengolahan Citra, dapat ditarik kesimpulan sebagai berikut:

- Dengan cara merubah citra RGB ke format citra grayscale lalu di substract dengan citra acuan ,menambah brightness, dan merubah ke format biner dengan Otsu's threshold dapat ditemukan objek berupa panjang antrian.

- Sistem dapat digunakan paling maksimal pada saat siang hari atau pada saat cuaca sedang cerah. Semakin terang kondisi jalan, maka semakin tinggi tingkat akurasi yang didapatkan. Pada pagi hari, didapatkan nilai error $1.74 \%$, pada siang hari didapatkan nilai error sebesar $9 \%$, pada malam hari dengan penerangan normal didapatkan nilai error sebesar $21 \%$ dan pada malam hari dengan tambahan penerangan didapat nilai error sebesar $15 \%$.

- Dengan 4 buah input berupa panjang antrian dari jalur di persimpangan, dapat dihitung lama lampu hijau dan lampu merah menyala menggunakan logika fuzzy tsukamoto.Penggunaan 4 buah input dimaksudkan agar setiap input akan memperhatikan jumlah antrian dari setiap jalur dan memperhatikan sebaran kepadatan,Sehingga hasil lama lampu merah dan lampu hijau yang didapatkan sesuai dengan sebaran kepadatan antrian.

\subsection{Saran}

Saran yang diberikan untuk pengembangan Sistem Pengaturan Lampu Lalu Lintas Berdasarkan Estimasi Panjang Antrian Menggunakan Pengolahan Citra adalah sebagai berikut:

- Sebaiknya menggunakan kamera webcam dengan resolusi yang lebih baik dan jangkauan yang lebih besar tanpa menggunakan lensa wide.Sehingga hasil pengambilan gambar dan proses pengolahan citra dapat mendapatkan hasil yang lebih maksimal.

- Penelitian dapat dikembangkan dengan mencari tempat peletakan kamera yang paling efektif, Sehingga mendapatkan hasil pengambilan gambar yang lebih maksimal.

- Memberi mikrocontroler lampu lalu lintas menyala pada prototype.

\section{Daftar Pustaka:}

Ioannis Pitas, 1993. "Digital Image Processing Algorithms", Prentice-Hall International.

Munir, Rinaldi , 2004. Pengolahan Citra Digital 
Volume 3, Edisi 3, Mei 2017

dengan Pendekatan Algoritmik.Informatika.

Rafael C. Gonzalez and Richard E. Woods,. 2002.

"Digital Image Processing", AddisonWesleyPublishing.

Rosnelly,Rika, 2012.Sistem Pakar : Konsep dan Teori.Yogyakarta:Andi.

Otsu, Nobuyuki, 1979. A Threshold Selection Method from Gray-Level Histograms. IEEE Vol.9 